\title{
Drain type after burr-hole drainage of chronic subdural hematoma in geriatric patients: a subanalysis of the cSDH-Drain randomized controlled trial
}

\author{
Ladina Greuter, MD, ${ }^{1}$ Katharina Lutz, MD, ${ }^{3}$ Javier Fandino, MD, ${ }^{4}$ Luigi Mariani, MD, ${ }^{1,2}$ \\ Raphael Guzman, MD,1,2 and Jehuda Soleman, MD ${ }^{1,2}$
}

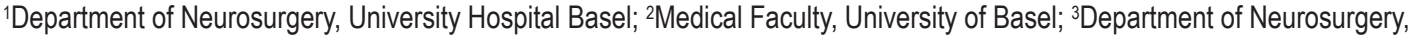
University Hospital Bern; and ${ }^{4}$ Department of Neurosurgery, Kantonsspital Aarau, Switzerland

\begin{abstract}
OBJECTIVE Chronic subdural hematoma (CSDH) occurs more frequently in elderly patients, while older patient age is associated with worse postoperative outcome following burr-hole drainage (BHD) of cSDH. The cSDH-Drain trial showed comparable recurrence rates after BHD and placement of either a subperiosteal drain (SPD) or subdural drain (SDD). Additionally, an SPD showed a significantly lower rate of infections as well as iatrogenic parenchymal injuries through drain misplacement. This post hoc analysis aims to compare recurrence rates and clinical outcomes following $\mathrm{BHD}$ of $\mathrm{CSDH}$ and the placement of SPDs or SDDs in elderly patients.
\end{abstract}

METHODS The study included 104 patients (47.3\%) 80 years of age and older from the 220 patients recruited in the preceding cSDH-Drain trial. SPDs and SDDs were compared with regard to recurrence rate, morbidity, mortality, and clinical outcome. A post hoc analysis using logistic regression, comparing the outcome measurements for patients $<80$ and $\geq 80$ years old in a univariate analysis and stratified for drain type, was further completed.

RESULTS Patients $\geq 80$ years of age treated with an SDD showed higher recurrence rates (12.8\%) compared with those treated with an SPD $(8.2 \%)$, without a significant difference $(p=0.46)$. Significantly higher drain misplacement rates were observed for patients older than 80 years and treated with an SDD compared with an SPD $(0 \%$ vs $20 \%$, $p=0.01)$. Comparing patients older than 80 years to younger patients, significantly higher overall mortality $(15.4 \%$ vs $5.2 \%, p=0.012), 30$-day mortality $(3.8 \%$ vs $0 \%, p=0.033)$, and surgical mortality $(2.9 \%$ vs $1.7 \%, p=0.034)$ rates were observed. Clinical outcome at the 12-month follow-up was significantly worse for patients $\geq 80$ years old, and logistic regression showed a significant association of age with outcome, while drain type had no association with outcome.

CONCLUSIONS The initial findings of the CSDH-Drain trial and the findings of this subanalysis suggest that SPD may be warranted in elderly patients. As opposed to drain type, patient age (> 80 years) was significantly associated with worse outcome, as well as higher morbidity and mortality rates.

https://thejns.org/doi/abs/10.3171/2020.7.FOCUS20489

KEYWORDS chronic subdural hematoma; octogenarian; geriatric; recurrence; subperiosteal drain; subdural drain; burr-hole drainage; elderly patients

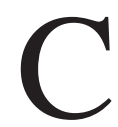
HRONIC subdural hematoma ( $\mathrm{cSDH})$ is one of the most common neurosurgical diseases, and its incidence increases with patient age.,18 The incidence rate of cSDH in patients 65-74 years of age is approximately 19 per 100,000 , whereas it increases to $47-153$ per 100,000 in patients older than 75 years. ${ }^{2}$ Older age carries a higher perioperative risk and is associated with worse outcomes in cSDH. 3.4

The gold standard of treatment remains surgical evacuation of the hematoma through burr-hole drainage (BHD) and insertion of a drain. ${ }^{5}$ Drain insertion after BHD was shown to significantly lower recurrence rates and improve

ABBREVIATIONS BHD = burr-hole drainage; $\mathrm{CAD}=$ coronary artery disease $; \mathrm{CCl}=$ Charlson Comorbidity Index; $\mathrm{cSDH}=\mathrm{chronic}$ subdural hematoma; $\mathrm{GCS}=\mathrm{Glasgow}$ Coma Scale; GOS = Glasgow Outcome Scale; LOS = length of stay; MLS = midline shift; mRS = modified Rankin Scale; MWS = Markwalder score; RCT = randomized controlled trial; SDD = subdural drain; SPD = subperiosteal drain.

SUBMITTED May 31, 2020. ACCEPTED July 17, 2020.

INCLUDE WHEN CITING DOI: 10.3171/2020.7.FOCUS20489. 
clinical outcome. ${ }^{6}$ Drains can be inserted either in the subdural space (subdural drains [SDDs]) or subperiosteally (subperiosteal drains [SPDs]); the recent cSDH-Drain randomized controlled trial (RCT) showed no significant difference in recurrence rate between the two drain types, but found significantly lower drain misplacement and infection rates in the SPD group.

This post hoc analysis aims to compare recurrence rates and clinical outcomes following BHD and the placement of SPDs or SDDs in elderly patients.

\section{Methods}

This is a subanalysis of the preceding cSDH-Drain trial. ${ }^{7}$ The original trial was registered with the ClinicalTrials.gov database (http://clinicaltrials.gov), and its registration no. is NCT01869855. The detailed methods of the cSDH-Drain trial can be found in two previous reports. ${ }^{7,8}$ In summary, the cSDH-Drain trial was a two-center RCT comparing SPDs to SDDs with regard to recurrence. Two hundred twenty patients were enrolled and randomized to either SPD or SDD placement following BHD of cSDH. Secondary outcome measures were clinical and radiological outcome measurements, drain misplacement rates, and morbidity and mortality. The follow-up time for all patients was 12 months. Recurrence was defined as radiological evidence of $\mathrm{cSDH}$ on the ipsilateral side with clinical symptoms requiring surgery within 12 months. Demographic data concerning preoperative clinical condition (age, sex, comorbidities, Glasgow Coma Scale [GCS] score, modified Rankin Scale [mRS] score, and Glasgow Outcome Scale [GOS] score), as well as radiological parameters (Markwalder score [MWS], midline shift [MLS], and diameter of hemorrhage), were assessed. Postoperatively, clinical follow-ups were obtained at 24 hours, 6 weeks, and 12 months, while clinical outcome was assessed through the GCS, mRS, GOS, and MWS. Radiological outcomes at 24 hours and 6 weeks included residual hematoma diameter and residual MLS.

From the patients initially recruited for the cSDH-Drain trial (220 patients: 120 treated with SDD, 100 treated with SPD), all patients $\geq 80$ years of age $(n=104)$ were included in this subanalysis. We compared the primary and secondary outcome measures from the cSDH-Drain trial between the different drain types. A post hoc analysis using logistic regression, comparing the outcome measurements for patients $<80$ and $\geq 80$ years old in a univariate analysis and stratified for drain type, was further completed. For this subanalysis, the outcome scores were dichotomized (GCS: good = 14-15, fair = 9-13, bad = 3-8; mRS: good = $1-3$, bad $=4-5$; GOS: $\operatorname{good}=4-5$, bad $=1-3$; and MWS: no/mild symptoms $=0-1$, significant symptoms $=2$, severe symptoms $=3-4)$. MLS and hemorrhage diameter were measured on the pre- and postoperative CT or MR images. Overall, 5 patients $(4.8 \%)$ were lost to follow-up, while for patients where recurrence and/or mortality occurred, follow-up from that point on was not undertaken. Therefore, at 6 weeks and 12 months, 93 and 78 patients, respectively, were followed. The initial trial was approved by the local ethics committee (EKNZ) and allows subanalysis of already registered data. Informed consent was obtained from all participants or their next of kin prior to randomization in the original RCT.

\section{Statistical Analysis}

Continuous variables were analyzed using the MannWhitney U-test and presented as median and interquartile range (IQR). The chi-square test or Fisher exact test, depending on the number of variables, was used for categorical data and presented as number of patients (percent). Logistic regression (categorical variables) or Poisson regression (continuous variables) analysis was conducted for significant variables in the univariate analysis to compare the association of different drainage types and age with the outcome parameters. Time to recurrence, overall mortality, and 30-day time to mortality of the drain types, stratified by the age groups, were compared using the logrank test and presented as Kaplan-Meier curves. A p value $<0.05$ was considered significant. The reference for odds ratio (OR) presented was the SDD group, unless otherwise stated. All analyses were performed using SPSS software (version 26, IBM Corp.) and R statistical software (version 3.6.2, The R Foundation). The analyses were performed on the per protocol analysis set as defined for the main trial analysis.

\section{Results}

Out of the 220 study participants, recruited between April 2013 and December 2015, 41 (18.6\%) were < 70 years, $75(34.1 \%)$ were $70-79$ years, and $104(47.3 \%)$ were $\geq 80$ years of age. For patients $\geq 80$ years of age, the distribution of SPDs and SDDs was well matched $(n=49$ and $\mathrm{n}=55$ ), while patients $<70$ years and $70-79$ years old received more SPDs $(<70$ years, $\mathrm{n}=28$ and 13; 70-79 years, $n=43$ and $n=32$ ); however, the difference was not significant $(\mathrm{p}=0.06)$.

The baseline characteristics of patients $<80$ and $\geq 80$ years old are presented in Table 1. Both groups were heterogenous, with significant differences concerning preexisting comorbidities, namely diabetes, coronary artery disease (CAD), atrial fibrillation, and dementia, resulting in a significantly higher Charlson Comorbidity Index (CCI) and more frequent blood thinner intake for patients $\geq 80$ years old when compared with patients $<80$ years of age. Furthermore, preoperative clinical outcome parameters were significantly worse in patients $\geq 80$ years old.

\section{Patients $\geq 80$ Versus $<80$ Years Old}

Patients older than 80 years showed a recurrence rate of $10.6 \%$ compared with $9.5 \%$ for patients younger than 80 years $(p=0.79)$. Time to recurrence was similar for both drain types regardless of age (Fig. 1).

When comparing patients under the age of 80 years to patients above the age of 80 years, overall mortality ( $15.4 \%$ vs $5.2 \%, \mathrm{p}=0.012), 30$-day mortality (3.8\% vs $0 \%, \mathrm{p}=0.033)$, and surgical mortality $(2.9 \%$ vs $1.7 \%, \mathrm{p}$ $=0.034)$ rates were significantly higher in patients $\geq 80$ years old. After logistic regression analysis, drain type had no association with mortality rate, while age significantly affected overall mortality (Table 2).

Additionally, patients older than 80 years showed sta- 
TABLE 1. Baseline characteristics for patients $<80$ and $\geq 80$ years old

\begin{tabular}{|c|c|c|c|}
\hline Variable & $<80$ Yrs & $\geq 80$ Yrs & p Value \\
\hline No. of patients & 116 & 104 & \\
\hline Mean age (SD), yrs & $70.21(8.67)$ & $85.10(3.67)$ & $<0.001$ \\
\hline Females & $38(32.8)$ & $33(31.7)$ & 0.99 \\
\hline GCS admission score & & & 0.007 \\
\hline Good (14-15) & 102 (87.9) & $77(74.0)$ & \\
\hline Fair $(9-13)$ & $10(8.6)$ & $25(24.0)$ & \\
\hline $\operatorname{Bad}(3-8)$ & $4(3.4)$ & $2(1.9)$ & \\
\hline mRS admission score & & & 0.001 \\
\hline Good (0-3) & $100(86.2)$ & $69(66.3)$ & \\
\hline $\operatorname{Bad}(4-5)$ & $16(13.8)$ & $35(33.7)$ & \\
\hline MWS admission & & & 0.009 \\
\hline No/mild symptoms (0-1) & $53(45.7)$ & $28(26.9)$ & \\
\hline Significant symptoms (2) & $60(51.7)$ & $69(66.3)$ & \\
\hline Severe symptoms (3-4) & $3(2.6)$ & $7(6.7)$ & \\
\hline GOS admission score & & & 0.002 \\
\hline Good (4-5) & $97(83.6)$ & $67(64.4)$ & \\
\hline $\operatorname{Bad}(1-3)$ & $19(16.4)$ & $37(35.6)$ & \\
\hline Aphasia & $22(19.0)$ & $25(24.0)$ & 0.452 \\
\hline Coma & $3(2.6)$ & $3(2.9)$ & 1.000 \\
\hline Motor deficit & $51(44.0)$ & $57(54.8)$ & 0.141 \\
\hline Incontinence & $4(3.4)$ & $2(1.9)$ & 0.780 \\
\hline Headache & $44(37.9)$ & $23(22.1)$ & 0.016 \\
\hline Sensory deficit & $10(8.6)$ & $4(3.8)$ & 0.241 \\
\hline Confusion & $40(34.5)$ & $63(60.6)$ & $<0.001$ \\
\hline Ataxia & $36(31.0)$ & $39(37.5)$ & 0.386 \\
\hline Seizures & $6(5.2)$ & $6(5.8)$ & 1.000 \\
\hline Diabetes & $10(8.6)$ & $20(19.2)$ & 0.036 \\
\hline Hypertension & $59(50.9)$ & $57(54.8)$ & 0.653 \\
\hline CAD & $25(21.6)$ & $38(36.5)$ & 0.021 \\
\hline COPD & $4(3.4)$ & $1(1.0)$ & 0.434 \\
\hline Kidney failure & $11(9.5)$ & $18(17.3)$ & 0.130 \\
\hline Dementia & $8(6.9)$ & $18(17.3)$ & 0.029 \\
\hline Liver failure/cirrhosis & $3(2.6)$ & $0(0)$ & 0.285 \\
\hline Obesity & $4(3.4)$ & $3(2.9)$ & 1.000 \\
\hline Atrial fibrillation & 14 (12.1) & $32(30.8)$ & 0.001 \\
\hline Smoker & $7(6.0)$ & $1(1.0)$ & 0.100 \\
\hline Alcohol abuse & $10(8.6)$ & $3(2.9)$ & 0.130 \\
\hline Valvular disease & $3(2.6)$ & $9(8.7)$ & 0.093 \\
\hline Stroke & $14(12.1)$ & $13(12.5)$ & 1.000 \\
\hline Pulmonary embolism & $3(2.6)$ & $5(4.8)$ & 0.604 \\
\hline DVT & $5(4.3)$ & $3(2.9)$ & 0.839 \\
\hline Other comorbidities & 57 (49.1) & $41(39.4)$ & 0.190 \\
\hline Mean CCl (SD) & $4.34(1.40)$ & $5.10(0.98)$ & $<0.001$ \\
\hline Blood thinner intake & $62(53.4)$ & $71(68.3)$ & 0.035 \\
\hline Hematoma side & & & 0.747 \\
\hline Rt & $47(40.5)$ & $37(35.6)$ & \\
\hline $\mathrm{Lt}$ & $46(39.7)$ & $44(42.3)$ & \\
\hline Bilat & $23(19.8)$ & $23(22.1)$ & \\
\hline
\end{tabular}

» CONTINUED FROM PREVIOUS COLUMN

TABLE 1. Baseline characteristics for patients $<80$ and $\geq 80$ years old

\begin{tabular}{lcrr}
\hline \multicolumn{1}{c}{ Variable } & $<80$ Yrs & $\geq 80$ Yrs & p Value \\
\hline Mean MLS preop (SD), mm & $7.09(5.24)$ & $7.51(5.07)$ & 0.545 \\
\hline $\begin{array}{l}\text { Mean hematoma width preop } \\
\text { (SD), mm }\end{array}$ & $18.06(7.16)$ & $19.91(8.00)$ & 0.071 \\
\hline Hematoma type & & & \\
\hline$\quad$ Chronic & $52(44.8)$ & $56(54.4)$ & \\
\hline Acute on chronic & $35(30.2)$ & $27(26.2)$ & \\
\hline Subacute & $28(24.1)$ & $20(19.4)$ & \\
\hline Hygroma & $1(0.9)$ & $0(0)$ & \\
\hline
\end{tabular}

COPD = chronic obstructive pulmonary disease; $D V T=$ deep vein thrombosis. Values are presented as number (\%) unless otherwise indicated. Boldface type indicates statistical significance.

tistically significant higher rates of medical complications $(20.2 \%$ vs $10.3 \%, \mathrm{p}=0.04)$ and overall complications $(37.5 \%$ vs $23.3 \%, p=0.022)$. After logistic regression analysis, drain type had no association with the medical complication rate, as opposed to age (Table 2).

Clinical outcome (mRS, GOS, and MWS) was significantly worse in patients $\geq 80$ years old compared with patients $<80$ years old at the 12-month follow-up. Logistic regression analysis showed a significant association for age but not for drain type with outcome (Table 2). Radiological outcome measured as residual cavity at 24 hours postoperatively was significantly higher in patients $\geq 80$ years old compared with patients $<80$ years old (11 mm [IQR 8-15 mm] vs $10 \mathrm{~mm}$ [IQR 7-13 mm], p $=0.01$ ), while MLS showed comparable results in both age groups. After logistic regression analysis, drain type had no association with residual cavity at 24 hours, as opposed to age (Table 2).

When comparing patients $\geq 80$ to those $<80$ years of age, length of stay (LOS) was significantly longer in older patients (7 days [IQR 5-10 days] vs 6 days [IQR 5-7 days], $\mathrm{p}=0.011$ ). After logistic regression analysis, age showed a significant association with LOS, while drain type had no association (Table 2).

\section{Comparing SDDs and SPDs in Patients $\geq 80$ Years Old}

The baseline characteristics of the two drain groups in patients $\geq 80$ years of age were well matched (Supplementary Table 1). Patients older than 80 years of age treated with an SDD showed recurrence rates of $12.8 \%$, compared with $8.2 \%$ when an SPD was inserted, without a significant difference $(p=0.46)$. Time to recurrence was comparable for both drain types as well (Fig. 2).

Overall mortality and 30-day mortality were comparable between the different drain types. Similarly, time to mortality and time to 30-day mortality were comparable for both drain types (Figs. 3 and 4). The SPD group showed a trend toward lower surgical mortality rates compared with the SDD group (0\% vs $5.5 \%, \mathrm{p}=0.07)$.

No drain misplacement was observed in the SPD group, which led to a significant difference between the groups $(0 \%$ vs $20 \%, \mathrm{p}=0.01)$. 

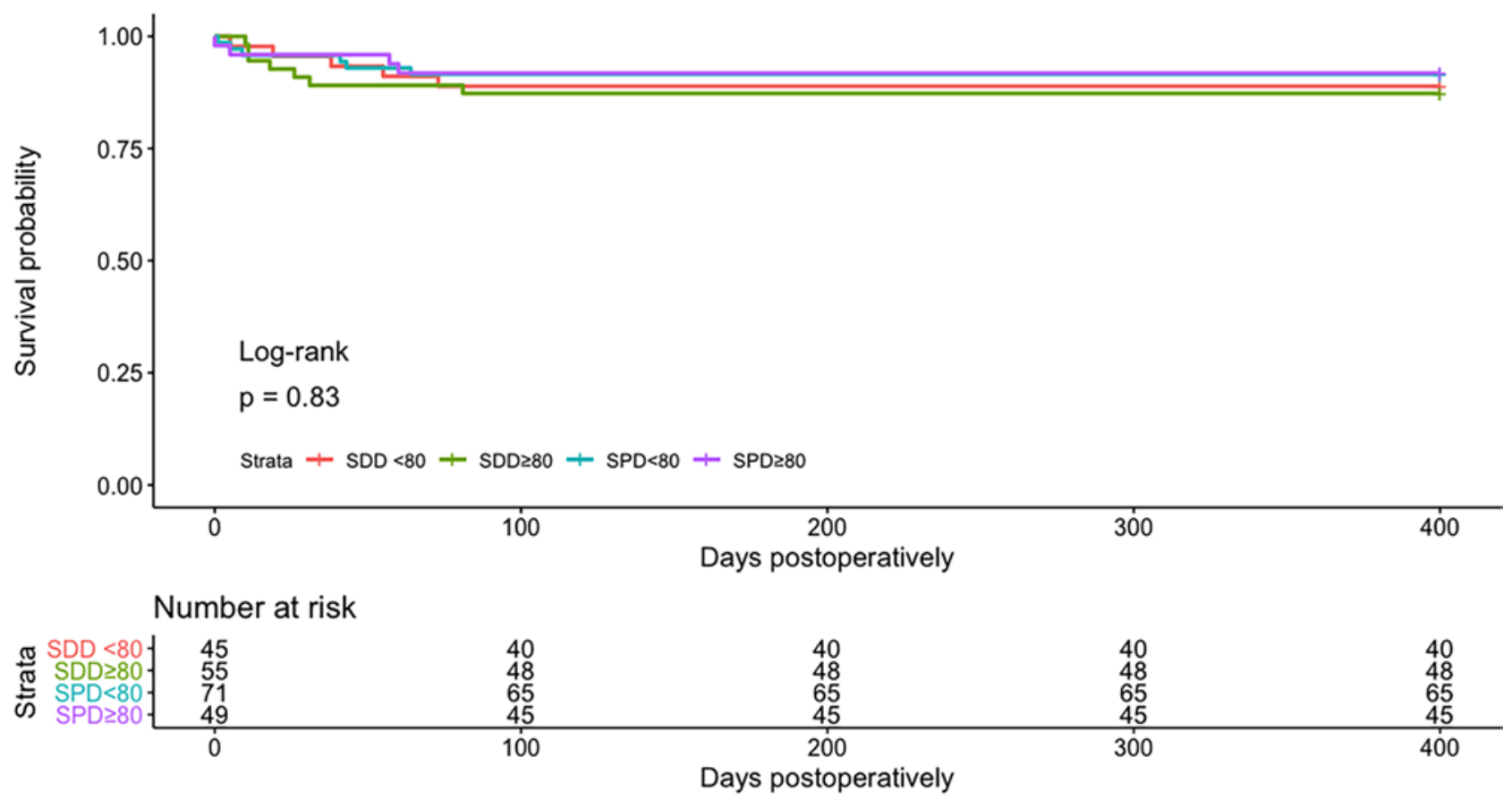

FIG. 1. Kaplan-Meier curve for time to recurrence for the different drain types stratified by age groups.

In general, clinical and radiological outcome measures were similar in both groups, with the exception of a statistically significant higher MWS at the last follow-up in the SDD group ( $n=12$ vs $n=3, p=0.049)$ and a lower residual MLS in the SPD group ( $n=3$ [IQR $0-4]$ vs $n=3$ [IQR 1-6], $\mathrm{p}=0.038$ ) 24 hours after surgery.

\section{Discussion}

To date, the cSDH-Drain trial is the largest study randomly comparing recurrence rates of surgically drained cSDH after the insertion of an SPD or SDD. As the incidence of cSDH increases with age, it is not surprising that 104 of the patients were over 80 years of age, showing the importance of analyzing the outcome after BHD of cSDH stratified by age. To date, no studies exist analyzing different operative techniques for cSDH that might affect outcome depending on the patient's age. It has been shown that older patients have overall worse outcome after surgical treatment of $\mathrm{cSDH} .{ }^{3}$ Our data showed that patients $\geq 80$ years old show higher complication and mortality rates. Hence, optimal surgical treatment is of paramount importance in geriatric patients.

The most commonly used method for $\mathrm{cSDH}$ treatment is BHD. ${ }^{5,9}$ BHD was shown to have significantly lower complication rates compared with open craniotomy, especially in elderly patients, while a trend toward higher complication rates as opposed to percutaneous twist-drill evacuation was observed., 90 Especially in older patients with high perioperative risks, BHD is preferred to craniotomy as it is less invasive, is associated with shorter operative duration, leads to lower morbidity, and can be performed under local anesthesia. BHD and open craniotomy were shown to be significantly superior to percutaneous twist-drill evacuation regarding recurrence rates. ${ }^{10}$ This is especially important in geriatric patients, since avoiding recurrences, which can potentially lead to reoperations, is paramount for achieving a good outcome in this group of patients. Therefore, it appears that BHD is also the treatment with the best risk-benefit ratio in elderly patients suffering from $\mathrm{cSDH} .{ }^{11}$

Conservative management is, to date, still reserved for patients with high perioperative risk or with mild symptoms. Several options were discussed in the literature, including administration of tranexamic acid, corticosteroids, mannitol, statins, or angiotensin-converting enzyme inhibitors. ${ }^{12}$ In a meta-analysis, the use of corticosteroids was shown to lack a significant difference concerning recurrence rate, morbidity, and mortality when compared with surgical treatment. ${ }^{9}$ However, ongoing RCTs are investigating the value of corticosteroids as stand-alone and adjacent treatment to surgery for $\mathrm{CSDH}^{13,14} \mathrm{~A}$ recent placebo-controlled RCT showed that atorvastatin significantly lowers hematoma volume and neurological symptoms as a stand-alone treatment of $\mathrm{cSDH} .{ }^{15}$ Hence, atorvastatin could be considered a pharmacological treatment, especially for geriatric patients who are often highrisk surgical candidates. Endovascular middle meningeal artery embolization has recently been described for the treatment of $\mathrm{cSDH}$. This technique was shown to have a high success rate and comparable complication rates to surgical treatment, but results from large studies are still lacking. ${ }^{16,17}$ In the future, minimally invasive methods and pharmacological treatments might play a greater role in the treatment of $\mathrm{cSDH}$ in geriatric patients presenting with comorbidities and a high perioperative risk. However, to date, surgery (BHD) remains the gold standard treatment for geriatric patients, while we eagerly anticipate results 
TABLE 2. Primary and secondary outcome measures in patients $<80$ and $\geq 80$ years old

\begin{tabular}{|c|c|c|c|c|}
\hline Outcome Measure & $\begin{array}{l}<80 \text { Yrs } \\
(n=116)\end{array}$ & $\begin{array}{l}\geq 80 Y r s \\
(n=104)\end{array}$ & $p$ Value & $\begin{array}{l}\text { Regression Analysis } \\
(\text { OR }[95 \% \mathrm{Cl}], \mathrm{p} \text { value })^{*}\end{array}$ \\
\hline Recurrence & $11(9.5)$ & $11(10.6)$ & 0.79 & \\
\hline \multicolumn{5}{|l|}{ Mortalities } \\
\hline Overall & $6(5.2)$ & $16(15.4)$ & 0.012 & $\begin{array}{l}\text { Age: } 1.08(1.02-1.16), 0.01 \\
\text { SPD: } 0.84(0.34-2.10), 0.70\end{array}$ \\
\hline 30-day & $0(0)$ & $4(3.8)$ & 0.033 & $\begin{array}{l}\text { Age: } 1.12(0.96-1.30), 0.15 \\
\text { SPD: } 1.0(0.14-7.32), 1.0\end{array}$ \\
\hline Surgical & $2(1.7)$ & $3(2.9)$ & 0.034 & $\begin{array}{l}\text { Age: } 1.00(0.91-1.10), 0.99 \\
\text { SPD: } 4.95 \text { (5.33-49.52), } 0.16\end{array}$ \\
\hline Postop bleeding $\dagger$ & $13(11.2)$ & $7(6.7)$ & 0.25 & \\
\hline Postop bleeding group & & & 0.30 & \\
\hline None & $103(88.8)$ & $97(93.3)$ & & \\
\hline aSDH & $7(6)$ & $5(4.8)$ & & \\
\hline $\mathrm{IPH}$ & $3(2.6)$ & $1(1)$ & & \\
\hline SAH & $3(2.6)$ & $0(0)$ & & \\
\hline $\mathrm{EDH}$ & $0(0)$ & $1(1)$ & & \\
\hline \multicolumn{5}{|l|}{ Misplaced drain } \\
\hline Total & $7(6)$ & $11(10.6)$ & 0.22 & \\
\hline Causing bleeding & $2(1.7)$ & $3(2.9)$ & 0.56 & \\
\hline Causing neurologic sequel & $1(0.9)$ & $1(1)$ & 0.94 & \\
\hline Surgical infection & $11(9.5)$ & $7(6.7)$ & 0.27 & \\
\hline Postop seizure & $4(3.4)$ & $7(6.7)$ & 0.46 & \\
\hline \multicolumn{5}{|l|}{ Complications } \\
\hline Surgical & $13(11.2)$ & $11(10.6)$ & 0.88 & \\
\hline Medical & $12(10.3)$ & $21(20.2)$ & 0.04 & $\begin{array}{l}\text { Age: } 1.04 \text { (1.00-1.09), } 0.07 \\
\text { SPD: } 0.90 \text { (0.42-1.91), } 0.78\end{array}$ \\
\hline Total & $27(23.3)$ & $39(37.5)$ & 0.022 & $\begin{array}{l}\text { Age: } 1.01(0.98-1.04), 0.57 \\
\text { SPD: } 0.75(0.41-1.35), 0.34\end{array}$ \\
\hline Revision surgery† & $6(5.2)$ & $7(6.7)$ & 0.63 & \\
\hline GCS score at 6 wks $\ddagger$ & & & 0.45 & \\
\hline Good (14-15) & $105(90.5)$ & $92(88.5)$ & & \\
\hline Fair $(9-13)$ & $3(2.6)$ & $1(1)$ & & \\
\hline Bad (3-8) & $1(0.9)$ & $0(0)$ & & \\
\hline $\mathrm{mRS}$ score at 6 wks & & & 0.07 & \\
\hline Good (0-3) & $103(88.8)$ & $81(77.9)$ & & \\
\hline $\operatorname{Bad}(4-5)$ & $6(5.2)$ & $12(11.5)$ & & \\
\hline MWS at 6 wks & & & 0.20 & \\
\hline No, mild symptoms (0-1) & $100(86.2)$ & $80(76.9)$ & & \\
\hline Significant symptoms (2) & $9(7.8)$ & $11(10.6)$ & & \\
\hline Severe symptoms (3-4) & $0(0)$ & $2(1.9)$ & & \\
\hline GOS score at 6 wks & & & 0.14 & \\
\hline Good (4-5) & $99(85.3)$ & $78(75)$ & & \\
\hline $\operatorname{Bad}(1-3)$ & $10(8.6)$ & $15(14.4)$ & & \\
\hline GCS score at 12 mos $\S$ & & & 0.44 & \\
\hline Good (14-15) & $95(81.9)$ & $76(73.1)$ & & \\
\hline Fair $(9-13)$ & $1(0.9)$ & $2(1.9)$ & & \\
\hline $\operatorname{Bad}(3-8)$ & $0(0)$ & $0(0)$ & & \\
\hline mRS score at 12 mos & & & 0.008 & \\
\hline Good (0-3) & $93(80.2)$ & $67(64.4)$ & & Age: 1.20 (1.07-1.33), 0.001 \\
\hline $\operatorname{Bad}(4-5)$ & $3(2.6)$ & $11(10.6)$ & & SPD: 0.62 (0.19-2.02), 0.43 \\
\hline
\end{tabular}


» CONTINUED FROM PAGE 5

TABLE 2. Primary and secondary outcome measures in patients $<80$ and $\geq 80$ years old

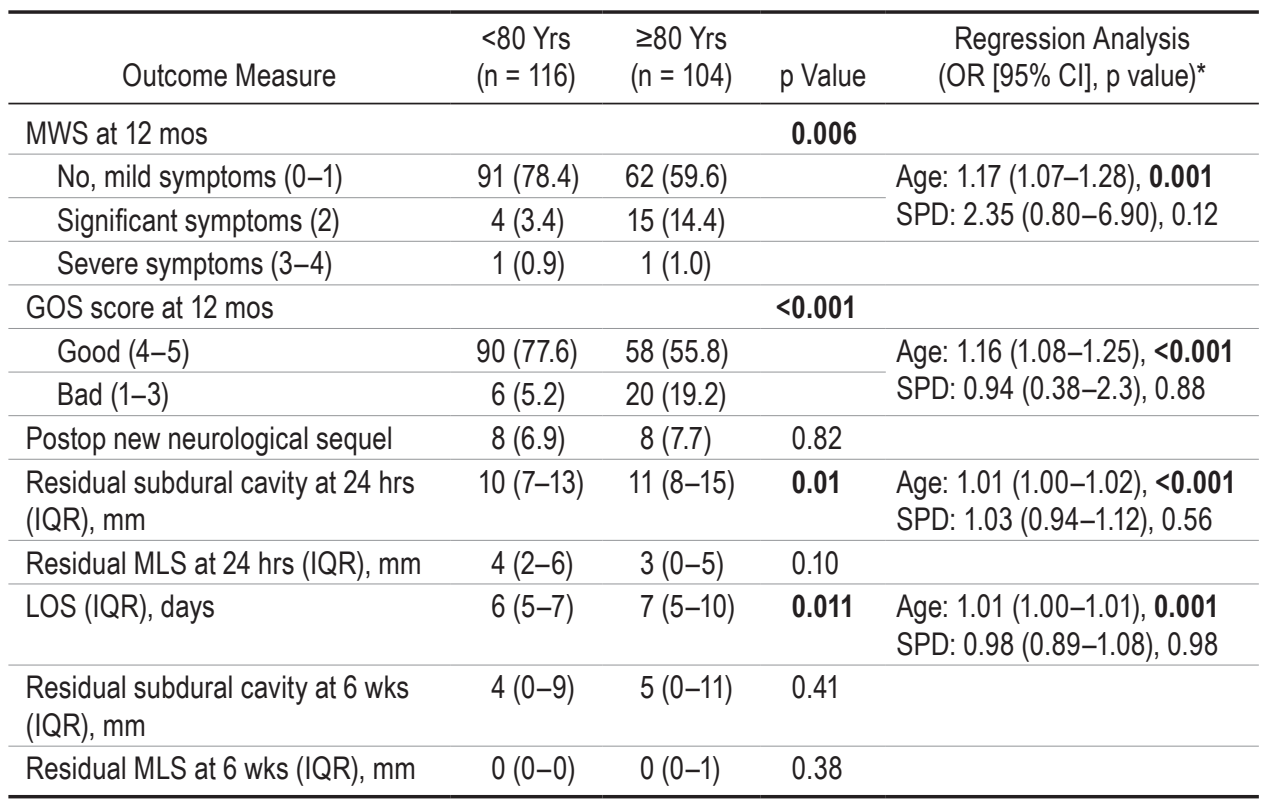

aSDH = acute subdural hematoma; EDH = epidural hematoma; IPH = intraparenchymal hematoma; $\mathrm{SAH}$ = subarachnoid hemorrhage.

Values are presented as number (\%) unless otherwise indicated. Boldface type indicates statistical significance.

* Logistic regression or Poisson regression analysis for significant variables in univariate analysis, analyzing for association of drain type and age with the variable.

† Postoperative bleeding and revision surgeries for recurrence not included.

$\ddagger$ At the 6-week follow-up, cohort $=202$.

$\S$ At the 12-week follow-up, cohort $=174$.

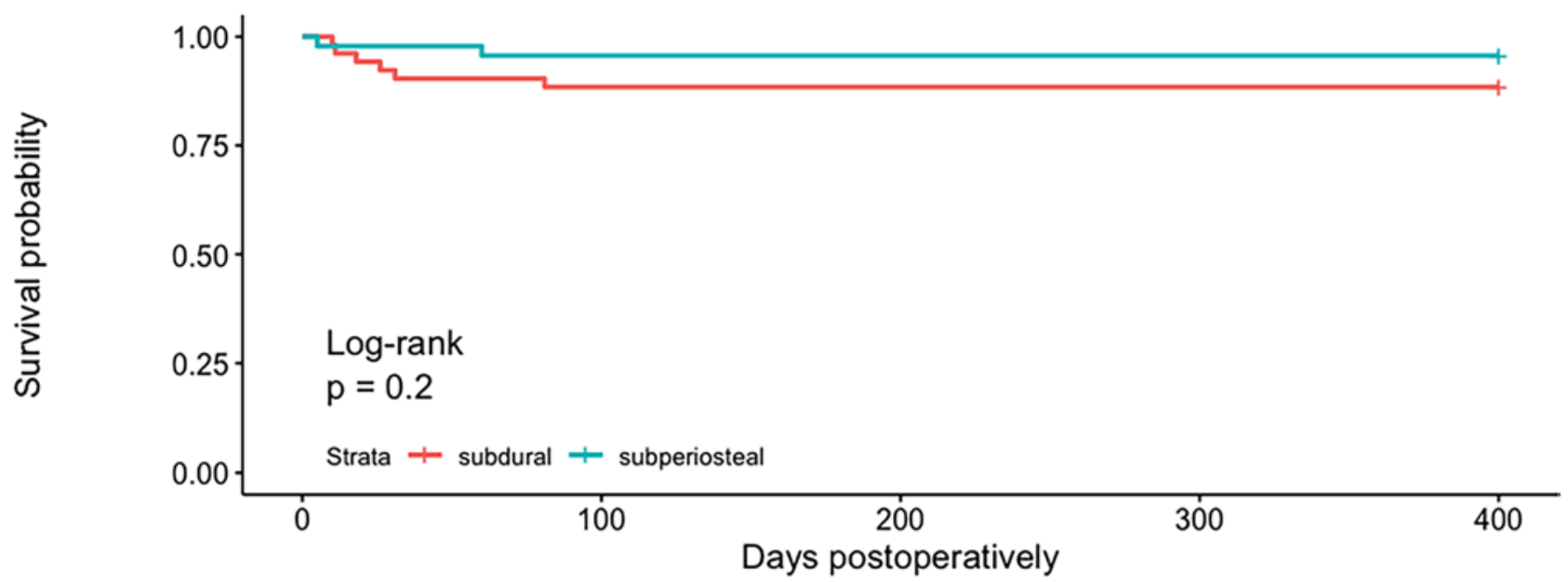

\section{Number at risk}

\begin{tabular}{|c|c|c|c|c|c|}
\hline $\begin{array}{l}\text { subdural } \\
\frac{\pi}{2} \\
\text { की }\end{array}$ & $\begin{array}{l}52 \\
46 \\
\end{array}$ & $\begin{array}{l}46 \\
44 \\
\end{array}$ & $\begin{array}{l}46 \\
44 \\
\end{array}$ & $\begin{array}{l}46 \\
44 \\
\end{array}$ & $\begin{array}{l}46 \\
44 \\
\end{array}$ \\
\hline & 0 & 100 & $\begin{array}{l}200 \\
\text { stop }\end{array}$ & 300 & 400 \\
\hline
\end{tabular}

FIG. 2. Kaplan-Meier curve for time to recurrence in patients $\geq 80$ years old stratified by different drain types. 

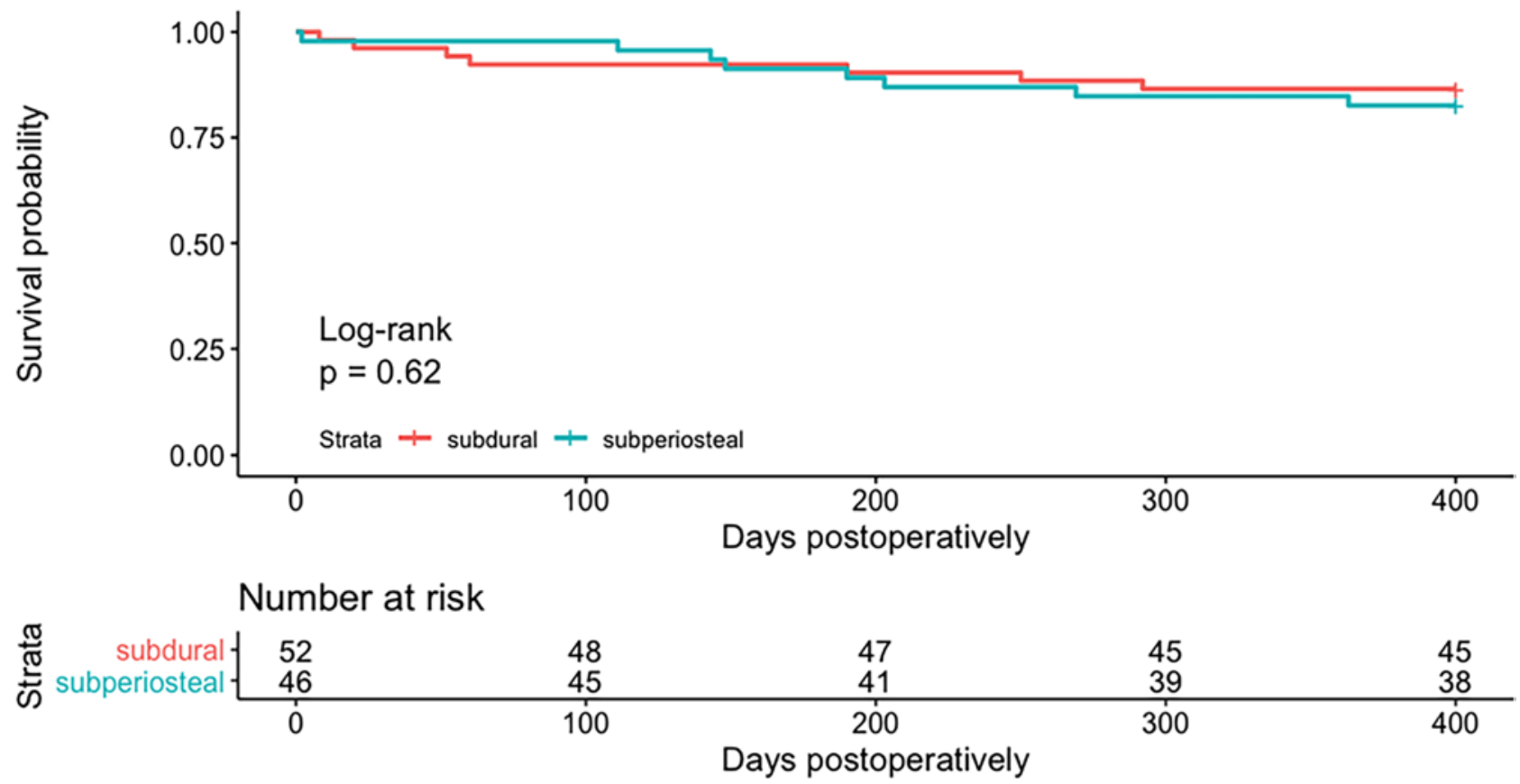

FIG. 3. Kaplan-Meier curve for time to overall mortality in patients $\geq 80$ years old stratified by different drain types.

from various prospective studies on pharmacological and other interventional treatment options. ${ }^{14}$

In general, recurrence rates for surgically evacuated $\mathrm{cSDH}$ are estimated to be around $10 \% .^{21}$ The main study and many other publications comparing SPD to SDD in regard to recurrence did not detect a statistically significant difference, except for a trend for a lower recurrence rate in the SPD group. A recent meta-analysis showed a significantly lower recurrence rate for SPD compared with SDD. ${ }^{19-22}$ Based on our subgroup analysis, lower recurrence rates were also noted for patients treated with SPD who were $\geq 80$ years old, without statistically significant differences. It seems, therefore, that SPD insertion in the geriatric population is comparable to SDD insertion, while the risk of drain misplacement can be avoided. Time to recurrence was comparable for both drain types in patients
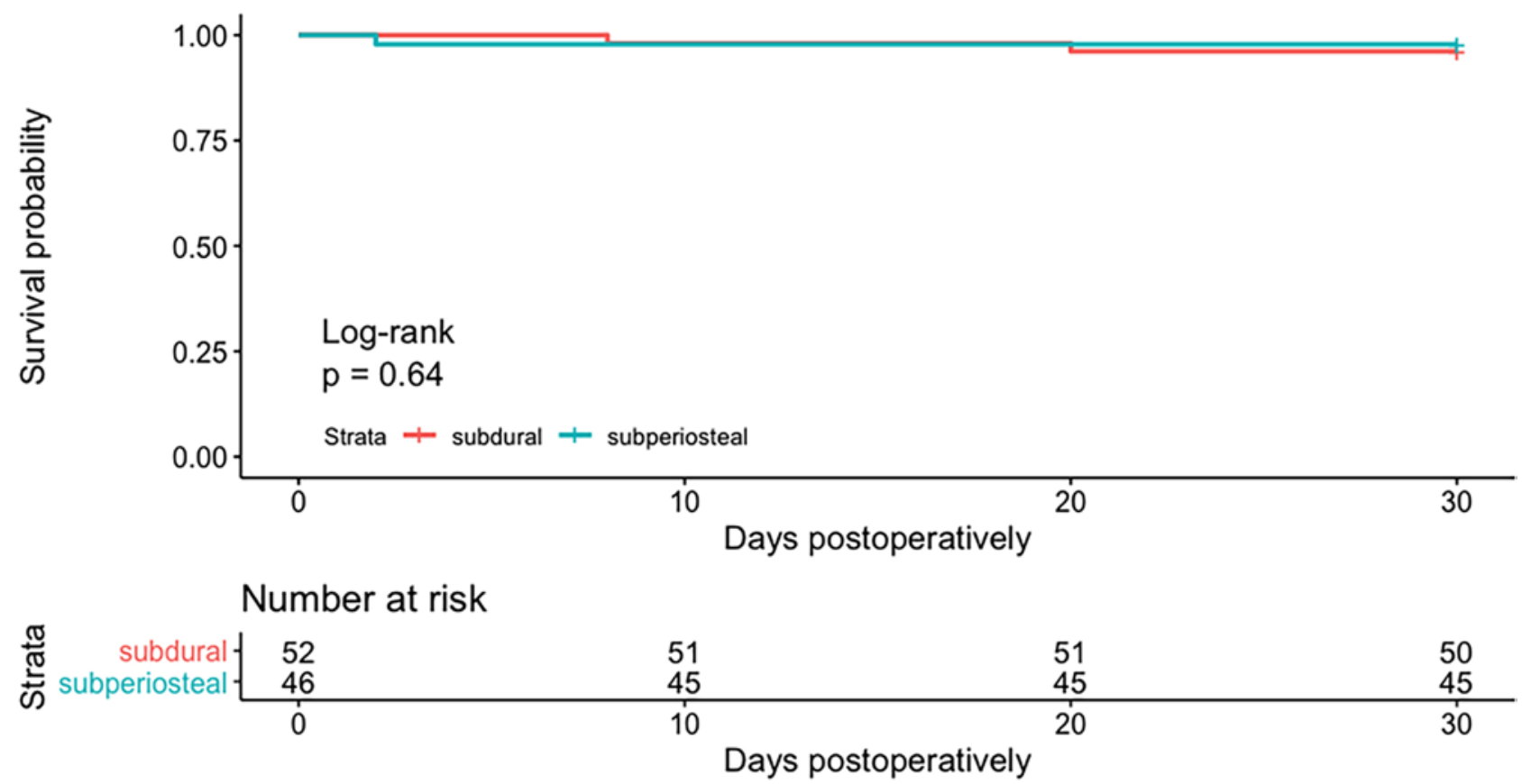

FIG. 4. Kaplan-Meier curve for time to 30 -day mortality in patients $\geq 80$ years old stratified by different drain types. 
$\geq 80$ years old; no difference was seen when also comparing patients $\geq 80$ and $<80$ years of age (Figs. 1 and 2). This finding is congruent with the recent subanalysis of the cSDH-Drain trial analyzing time to recurrence for the entire study population. ${ }^{23}$ Based on a recently published survey, many surgeons tend to insert an SPD only when intraoperative brain expansion after BHD occurs. ${ }^{5,24}$ Otherwise, an SDD is generally preferred because it is considered to be safe by some surgeons. However, based on the available literature, this practice is not justified, $7,23,25,26$ Studies have shown that even when a large residual subdural cavity is apparent, the risk for drain misplacement, potentially leading to bleeding and neurological deficits, is present. ${ }^{7,27}$ Elderly patients often show brain atrophy, which explains the significant difference in preoperative MLS and hematoma diameter between patients $<80$ and $\geq 80$ years old in our cohort (results not shown). Similarly, postoperative residual subdural cavity diameter (representing the amount of intraoperative brain expansion) and MLS were significantly higher in the geriatric population, indicating less intraoperative brain expansion (Table 2). Therefore, the tendency of most surgeons would probably be to place an SDD. However, the risk for drain misplacement in geriatric patients is also significantly higher in the SDD group (Table 2). The results of this subanalysis suggest that an SPD may be warranted for geriatric patients usually showing minimal intraoperative brain expansion, because recurrence rates are comparable to SDD and drain misplacement is avoided. In addition, approximately $65 \%$ of these patients are receiving blood thinner treatment, and therefore manipulation within the subdural space should be avoided whenever possible. . $^{23,25}$

Older age predisposes patients to more complications, consequently resulting in higher mortality rates. Mortality rates for cSDH in geriatric patients can occur in as many as $20 \%$ of the cases. ${ }^{4}$ Our cohort showed a total complication rate of $37.5 \%$ and 30 -day mortality rate of approximately $4 \%$ in patients $\geq 80$ years of age.

Overall complication and mortality rates were comparable for the SPD and SDD groups in patients $\geq 80$ years old. Surgical mortality, however, showed a trend toward higher rates within the SDD group (5.5\% vs $0 \%, \mathrm{p}=0.07)$. To evaluate the validity of these results, larger cohorts with adequate power are probably needed. Overall, patients $\geq$ 80 years old showed higher risk for complications and mortality as opposed to younger patients. The higher frequency of preexisting comorbidities in patients $\geq 80$ years old (results not shown) could explain these results.

The existing data concerning postoperative infection in the different drain types vary in the literature; the cSDHDrain trial has shown statistically significantly fewer infections in the SPD group. ${ }^{5,28}$ Although in the geriatric group the infection rate was slightly higher in the SDD group compared with the SPD group (7.3\% vs 6.1\%), significance was not observed. Because this subanalysis was probably underpowered, further studies powered for the detection of infection rates within the different drain types are needed to confirm our results.

Currently, only one study has shown a favorable outcome for patients treated with an SPD compared with an $\mathrm{SDD}$ after BHD of $\mathrm{cSDH} .{ }^{29}$ In this subanalysis, similar outcomes were observed at 24 hours, 6 weeks, and 12 months of follow-up for the different drain types in patients $\geq 80$ years old, with the exception of higher rates of severe symptoms based on the MWS at 12 months of follow-up in the SDD group. These findings are congruent with the main study? Additionally, worse outcome measures at presentation as well as at the last follow-up were observed for geriatric patients. Further prospective studies designed to analyze the outcome after insertion of an SPD compared with an SDD in cSDH are required.

\section{Limitations}

Because this study is a subanalysis of an RCT, it was not designed or powered to study the outcome measurements of SPD and SDD in geriatric patients. Hence, the results might be underpowered and need to be analyzed with caution. As cSDH is a disease of the elderly, most patients in our cohort were older than 70 years of age and no comparison to a younger subgroup is possible, but this reflects daily neurosurgical practice. However, comparing patients younger and older than 80 years of age led to sufficient patients in both cohorts, while the size of the cohorts and the baseline parameters in both drain groups were evenly matched. The strengths of this study are the prospectively collected subset of data, presented from the largest RCT analyzing recurrence rate and outcome after BHD of cSDH and insertion of an SPD compared with an SDD. The rather low rate of patients lost to follow-up presents an additional strength. To date, this is the first study analyzing which drain type appears to be more suitable for patients undergoing BHD of cSDH at $\geq 80$ years old.

\section{Conclusions}

Similar recurrence, complication, and mortality rates were observed for SPD compared with SDD in geriatric patients. Like the results of the cSDH-Drain trial, the rate of drain misplacement in the SDD group was significantly higher in geriatric patients, although postoperative brain expansion was significantly lower in patients $\geq 80$ years old when compared with younger patients. Of all outcome parameters, only the MWS was significantly worse in the SDD group at the last follow-up (12 months). A trend for higher surgical complication rates was seen in the SDD group. These results suggest that the insertion of an SPD after BHD of cSDH may be warranted in geriatric patients as well. As opposed to the type of drain inserted, patient age ( $>80$ years) was significantly associated with worse outcome, as well as higher morbidity and mortality rates, resulting in significantly longer hospital stays.

\section{References}

1. Yang W, Huang J. Chronic subdural hematoma: epidemiology and natural history. Neurosurg Clin N Am. 2017;28(2): 205-210.

2. Adhiyaman V, Chattopadhyay I, Irshad F, et al. Increasing incidence of chronic subdural haematoma in the elderly. QJM. 2017;110(6):375-378.

3. Christopher E, Poon MTC, Glancz LJ, et al. Outcomes following surgery in subgroups of comatose and very elderly patients with chronic subdural hematoma. Neurosurg Rev. 2019;42(2):427-431. 
4. Kuhn EN, Erwood MS, Oster RA, et al. Outcomes of subdural hematoma in the elderly with a history of minor or no previous trauma. World Neurosurg. 2018;119:e374-e382.

5. Soleman J, Kamenova M, Lutz K, et al. Drain insertion in chronic subdural hematoma: an international survey of practice. World Neurosurg. 2017;104:528-536.

6. Santarius T, Kirkpatrick PJ, Ganesan D, et al. Use of drains versus no drains after burr-hole evacuation of chronic subdural haematoma: a randomised controlled trial. Lancet. 2009; 374(9695):1067-1073

7. Soleman J, Lutz K, Schaedelin S, et al. Subperiosteal vs subdural drain after burr-hole drainage of chronic subdural hematoma: a randomized clinical trial (cSDH-Drain-Trial). Neurosurgery. 2019;85(5):E825-E834.

8. Soleman J, Lutz K, Schaedelin S, et al. Use of subperiosteal drain versus subdural drain in chronic subdural hematomas treated with burr-hole trepanation: study protocol for a randomized controlled trial. JMIR Res Protoc. 2016;5(2):e38.

9. Almenawer SA, Farrokhyar F, Hong C, et al. Chronic subdural hematoma management: a systematic review and metaanalysis of 34,829 patients. Ann Surg. 2014;259(3):449-457.

10. Weigel R, Schmiedek P, Krauss JK. Outcome of contemporary surgery for chronic subdural haematoma: evidence based review. J Neurol Neurosurg Psychiatry. 2003;74(7): 937-943.

11. Rovlias A, Theodoropoulos S, Papoutsakis D. Chronic subdural hematoma: surgical management and outcome in 986 cases: a classification and regression tree approach. Surg Neurol Int. 2015;6(1):127.

12. Soleman J, Nocera F, Mariani L. The conservative and pharmacological management of chronic subdural haematoma. Swiss Med Wkly. 2017;147:w14398.

13. Kolias AG, Edlmann E, Thelin EP, et al. Dexamethasone for adult patients with a symptomatic chronic subdural haematoma (Dex-CSDH) trial: study protocol for a randomised controlled trial. Trials. 2018;19(1):670.

14. Edlmann E, Holl DC, Lingsma HF, et al. Systematic review of current randomised control trials in chronic subdural haematoma and proposal for an international collaborative approach. Acta Neurochir (Wien). 2020;162(4):763-776.

15. Jiang R, Zhao S, Wang R, et al. Safety and efficacy of atorvastatin for chronic subdural hematoma in Chinese patients: a randomized clinical trial. JAMA Neurol. 2018;75(11):13381346.

16. Link TW, Boddu S, Paine SM, et al. Middle meningeal artery embolization for chronic subdural hematoma: a series of 60 cases. Neurosurgery. 2019;85(6):801-807.

17. Srivatsan A, Mohanty A, Nascimento FA, et al. Middle meningeal artery embolization for chronic subdural hematoma: meta-analysis and systematic review. World Neurosurg. 2019; 122:613-619.

18. Baechli H, Nordmann A, Bucher HC, Gratzl O. Demographics and prevalent risk factors of chronic subdural haematoma: results of a large single-center cohort study. Neurosurg Rev. 2004;27(4):263-266.

19. Ding H, Liu S, Quan X, et al. Subperiosteal versus subdural drain after burr hole drainage for chronic subdural hematomas: a systematic review and meta-analysis. World Neurosurg. 2020;136:90-100.

20. Greuter L, Hejrati N, Soleman J. Type of drain in chronic subdural hematoma-a systematic review and meta-analysis. Front Neurol. 2020;11:312.

21. Pranata R, Deka H, July J. Subperiosteal versus subdural drainage after burr hole evacuation of chronic subdural hematoma: systematic review and meta-analysis. Acta Neurochir (Wien). 2020;162(3):489-498.
22. Xie Y, Lu Q, Lenahan C, et al. A comparison of subperiosteal or subgaleal drainage with subdural drainage on the outcome of chronic subdural hematoma: a meta-analysis. World Neurosurg. 2020;135:e723-e730.

23. Lutz K, Kamenova M, Schaedelin S, et al. Time to and possible risk factors for recurrence after burr-hole drainage of chronic subdural hematoma: a subanalysis of the cSDHDrain randomized controlled trial. World Neurosurg. 2019; 132:e283-e289.

24. Laldjising ERA, Cornelissen FMG, Gadjradj PS. Practice variation in the conservative and surgical treatment of chronic subdural hematoma. Clin Neurol Neurosurg. 2020;195: 105899.

25. Kamenova M, Lutz K, Schaedelin S, et al. Subperiosteal versus subdural drain after burr-hole drainage under blood thinners: a subanalysis of the cSDH-Drain RCT. World Neurosurg. 2020;139:e113-e120.

26. Glancz LJ, Poon MTC, Coulter IC, et al. Does drain position and duration influence outcomes in patients undergoing burr-hole evacuation of chronic subdural hematoma? Lessons from a UK multicenter prospective cohort study. Neurosurgery. 2019;85(4):486-493.

27. Kamenova M, Wanderer S, Lipps $P$, et al. When the drain hits the brain. World Neurosurg. 2020;138:e426-e436.

28. Karibe H, Kameyama M, Kawase M, et al. Epidemiology of chronic subdural hematomas. Article in Japanese. No Shinkei Geka. 2011;39(12):1149-1153.

29. Kaliaperumal C, Khalil A, Fenton E, et al. A prospective randomised study to compare the utility and outcomes of subdural and subperiosteal drains for the treatment of chronic subdural haematoma. Acta Neurochir (Wien). 2012;154(11): 2083-2089.

\section{Disclosures}

The authors report no conflict of interest concerning the materials or methods used in this study or the findings specified in this paper.

\section{Author Contributions}

Conception and design: Soleman, Greuter. Acquisition of data: Lutz. Analysis and interpretation of data: Soleman, Greuter. Drafting the article: Greuter. Critically revising the article: Soleman, Greuter, Fandino, Mariani, Guzman. Reviewed submitted version of manuscript: all authors. Statistical analysis: Soleman, Greuter. Study supervision: Soleman.

\section{Supplemental Information}

\section{Online-Only Content}

Supplemental material is available online.

Supplementary Table 1. https://thejns.org/doi/suppl/10.3171/ 2020.7.FOCUS20489.

\section{Correspondence}

Jehuda Soleman: University Hospital Basel, Switzerland. jehuda.soleman@gmail.com. 